\title{
Modelagem integrada do problema de programação de tripulantes de aeronaves
}

\author{
Wagner de Paula Gomes ${ }^{1}$ e Nicolau Dionísio Fares Gualda ${ }^{2}$
}

\begin{abstract}
Resumo: Este artigo trata o Problema de Programação de Tripulantes (PPT), de importância fundamental no planejamento operacional das empresas aéreas. O PPT é normalmente dividido na literatura em dois subproblemas, formulados e resolvidos sequencialmente: Problema de Determinação das Viagens (PDV) e Problema de Atribuição de Escalas (PAE). Esta decomposição justifica-se pela sua natureza combinatória, porém deixa de proporcionar um tratamento global ao PPT, em termos de custo e qualidade da solução final. Portanto, o estado da arte envolve a solução integrada do PPT. O problema, no entanto, é NP-Difícil. Esta pesquisa apresenta uma metodologia para modelagem integrada do PPT através de um Algoritmo Genético Híbrido (AGH) associado a um procedimento de busca em profundidade e a um modelo de programação linear inteira, levando em conta as particularidades da legislação brasileira. A metodologia foi testada, com sucesso, para a solução de instâncias baseadas na malha real de uma empresa aérea brasileira.
\end{abstract}

Palavras-chave: transporte aéreo; programação de tripulantes; meta-heurística; algoritmo genético híbrido.

\begin{abstract}
This paper treats the Crew Scheduling Problem (CSP), important part of the airlines operational planning. The CSP is usually divided in the literature into two subproblems, formulated and solved sequentially: Crew Pairing Problem (CPP) and Crew Rostering Problem (CRP). This decomposition is justified by its combinatorial nature, but it does not provide a global treatment to the CSP, in terms of cost and quality of final solution. Therefore, the state of the art involves the integrated solution of CSP. The problem, however, is NP-Hard. This research presents a methodology for an integrated modeling of the CSP through a Hybrid Genetic Algorithm (HGA) associated with a depth-first search procedure and an integer linear programming model, taking into account the Brazilian crew legislation. The methodology was tested, with success, to solve instances related to the network of a Brazilian airline.
\end{abstract}

Keywords: air transportation; airline crew assignment; metaheuristic; hybrid genetic algorithm.

\section{INTRODUÇÃO}

Após os custos com combustíveis, os custos com tripulantes representam a maior parcela dos custos operacionais de uma empresa aérea (cerca de $20 \%$ do custo operacional total), o que leva à necessidade de uma atenção especial na gestão de sua tripulação (Cabral et al., 2000; Kohn e Karisch, 2004).

O principal objetivo do Problema de Programação de Tripulantes (PPT) é atribuir o conjunto de voos planejados para um dado período de tempo ao conjunto de tripulantes, considerando as regulamentações trabalhistas, as regras de segurança e as políticas das empresas, de tal maneira que o custo total da tripulação seja mínimo (Barnhart et al., 2003; Kohn e Karisch, 2004; Gopalakrishnan e Johnson, 2005).

O PPT é da classe NP-Difícil (Andersson et al., 1998), o que dificulta (ou impossibilita), em instâncias reais, a sua solução por métodos exatos, levando à necessidade de utilização de heurísticas ou meta-heurísticas para tal. A metodologia proposta nesta pesquisa objetiva a modelagem integrada do PPT atendendo à legislação brasileira, através de um Algoritmo Genético Híbrido (AGH) associado a um procedimento de busca em profundidade e a um modelo de programação linear inteira.

Na seção 2 deste artigo é apresentada uma visão geral do PPT, bem como uma revisão bibliográfica. A Seção 3 des-

\footnotetext{
${ }^{1}$ Wagner de Paula Gomes, Departamento de Engenharia de Transportes, Escola Politécnica, Universidade de São Paulo, São Paulo, SP, Brasil. (email:wagomes@usp.br).

${ }^{2}$ Nicolau Dionísio Fares Gualda, Departamento de Engenharia de Transportes, Escola Politécnica, Universidade de São Paulo, São Paulo, SP, Brasil. (e-mail: ngualda@usp.br).
}

Manuscrito recebido em 25/2/2010 e aprovado para publicação em 6/5/2011. Este artigo é parte de TRANSPORTES v.19, n.1, 2011. ISSN: 2237-1346 (online). creve a metodologia proposta e a Seção 4 apresenta os resultados dos testes e aplicações práticas do modelo. A Seção 5 apresenta as conclusões desta pesquisa.

\section{CARACTERIZAÇÃO DO PROBLEMA}

A cobertura de cada voo de uma empresa aérea requer um conjunto de tripulantes de categorias distintas: técnicos e não técnicos. Os tripulantes técnicos (pilotos) são qualificados para operar um tipo específico de aeronave ou um conjunto de aeronaves similares, denominado frota ou família de aeronaves. Os tripulantes não técnicos (comissários de bordo) podem ser qualificados para operar um conjunto maior de aeronaves distintas. Portanto, o PPT pode ser resolvido separadamente para cada categoria de tripulante (técnicos e não técnicos), sem afetar a qualidade da solução final.

O PPT tratado neste trabalho é definido como o problema de atribuir um conjunto de voos de um dado tipo de aeronave ao conjunto de tripulantes de mesma categoria (neste caso, apenas tripulantes técnicos), qualificados para operar este tipo de aeronave. Cada tripulante possui um calendário individual de disponibilidade, o qual leva em conta um conjunto de atividades previamente atribuídas, tais como treinamentos, férias, exames periódicos, reuniões e folgas. Além disso, cada tripulante está associado a uma base domiciliar (Crew Base), a qual é a localidade onde mantém domicílio e recebe suas folgas.

A entrada de dados do PPT é o conjunto de voos a ser coberto. Inicialmente, os voos são agrupados para formar as jornadas, que são séries de voos sequenciais equivalentes a um dia de trabalho de um tripulante. Em seguida, as jornadas são atribuídas aos tripulantes, considerando as regras e regulamentações vigentes, a disponibilidade dos tripulantes, a cobertura de todos os voos exatamente uma vez, e a mi- 
nimização do custo total da tripulação.

As regras e regulamentações aplicáveis ao PPT no contexto brasileiro (que satisfazem as normas internacionais) são (ANAC, 2010; SNA, 2010):

- Em uma jornada, os voos devem ser sequenciais no espaço e no tempo;

- O intervalo entre dois voos consecutivos deve respeitar um tempo mínimo e um tempo máximo, denominados minsit e maxsit, respectivamente, préestabelecidos por aeroporto em função de sua infraestrutura e das características operacionais das aeronaves;

- O início de uma jornada deve ocorrer no mínimo 30 minutos antes do horário previsto para partida do seu primeiro voo (tempo de preparação ou brief time);

- O término de uma jornada deve ocorrer no mínimo 30 minutos após o horário previsto para chegada do seu último voo (tempo de encerramento ou debrief time);

- A duração de uma jornada, incluindo os tempos de brief e debrief, deve ser de no máximo 11 horas (maxelapse);

- O tempo total de voo (ou total de horas de voo) e o número de pousos em uma mesma jornada são limitados a $9 \frac{1}{2}$ horas e 5 pousos. As empresas que utilizam aeronaves convencionais ou turboélice podem acrescentar 4 pousos ao limite pré-estabelecido;

- Entre duas jornadas deve haver um intervalo mínimo de 12 horas (repouso);

- Cada tripulante deve retornar à sua base domiciliar em no máximo 6 dias;

- Cada tripulante deve receber no mínimo 8 folgas por mês em sua base domiciliar, sendo 2 folgas consecutivas em um final de semana (uma no sábado e a outra no domingo) e pelo menos 1 folga por semana;

- O tempo total de voo das jornadas atribuídas a cada tripulante não deve exceder, em cada mês, trimestre ou ano, respectivamente: para aeronaves convencionais: 100, 270 e 1.000 horas; para aeronaves turboélice: 100, 255 e 935 horas; para aeronaves a jato: 85, 230 e 850 horas;

- A duração do trabalho (tempo total de voo e serviço em terra) de cada tripulante não deve exceder a 44 horas semanais e 176 horas mensais;

- Os tripulantes recebem um salário fixo por 54 horas de voo mensais (garantia mínima) e um salário adicional por hora de voo excedente;

- Como critério de qualidade, o total de horas de voo deve ser balanceado entre os tripulantes, visando à equiparação de salários.

\subsection{O problema na literatura}

Dada a sua natureza combinatória, o PPT é normalmente dividido na literatura em dois subproblemas, formulados e resolvidos sequencialmente: Problema de Determinação das Viagens - PDV (Crew Pairing Problem) e Problema de Atribuição das Escalas - PAE (Crew Rostering / Assignment Problem). O PDV busca fornecer um conjunto ótimo de viagens que cobre todos os voos planejados. Em seguida, no PAE, a melhor combinação de escalas (compostas pelas viagens do PDV e outras atividades pré-definidas) para os tripulantes é determinada, buscando a cobertura ótima dos voos e, eventualmente, o balanceamento de trabalho entre os tripulantes (Andersson et al., 1998; Barnhart et al., 2003; Kohn e Karisch, 2004; Gopalakrishnan e Johnson, 2005).

Viagem (Rotação, Chave de Voo, Pairing ou Trip Rotation) é o trabalho realizado pelo tripulante, contado desde a saída de sua base domiciliar até o regresso à mesma, caracterizando um ciclo. Uma viagem pode ser formada por uma ou mais jornadas (ANAC, 2010).

As estratégias para a solução sequencial do PPT são baseadas no princípio "gerar e otimizar", em que os subproblemas PDV e PAE são usualmente modelados como um problema de particionamento (ou cobertura) de conjuntos. Neste caso, as variáveis são equivalentes às viagens viáveis (PDV) e às escalas viáveis (PAE), e as regras e regulamentações impostas são aplicadas apenas no estágio de geração, implícito no modelo. No segundo estágio, a otimização dos subproblemas é realizada considerando a cobertura ótima de todos os voos (Barnhart et al., 2003; Kohn e Karisch, 2004; Gopalakrishnan e Johnson, 2005; Gomes e Gualda, 2008).

Esta divisão ocorre, pois a forma mais simples de caracterizar as viagens e as escalas matematicamente é através de enumeração. Por outro lado, implica dificuldades, já que o número de variáveis pode ser relativamente grande, em muitas instâncias reais, sendo impossível a sua enumeração total em tempo de processamento aceitável (Andersson et al., 1998; Gopalakrishnan e Johnson, 2005).

A busca em profundidade (Depth-First Search) e o algoritmo de caminho mínimo com restrição de recursos (Shortest Path with Resource Constraints) aplicados às redes espaço-tempo são os métodos mais adotados no estágio de geração do PDV e do PAE. No estágio de otimização, estratégias baseadas em métodos heurísticos ou metaheurísticas têm sido adotadas (Cabral et al., 2000; Chang, 2002; Lucic e Teodorovic, 2007). Já os métodos exatos são empregados apenas em problemas de pequeno porte (Andersson et al., 1998; Barnhart et al., 2003; Gopalakrishnan e Johnson, 2005; Gomes e Gualda, 2008).

A decomposição do PPT em dois subproblemas reduz a sua complexidade de solução, porém não conduz a uma estimativa real de custo e influi na qualidade da solução final. No PDV, o custo total do conjunto de viagens selecionado é minimizado, mas o custo real da programação só pode ser apurado após a atribuição das viagens aos diversos tripulantes, ou seja, após a solução do PAE, já que os tripulantes recebem um salário fixo por uma dada quantidade de horas de voo por mês e um salário adicional por hora de voo excedente. Além disso, a disponibilidade dos diversos tripulantes não é considerada na solução do PDV. Dessa forma, podem surgir conflitos durante a atribuição das escalas aos tripulantes no PAE, ocasionando custos extras e perda de qualidade da solução final. Para contornar tais desvantagens, o estado da arte do PPT envolve uma solução integrada, em que ambos os subproblemas (PDV e PAE) são resolvidos simultaneamente (Zeghal e Minoux, 2006; Gomes, 2009; Souai e Teghem, 2009).

Estratégias para a solução integrada do PPT ainda são escassas na literatura. Zeghal e Minoux (2006) propuseram uma estratégia para a solução integrada do PPT através de uma abordagem com duas fases distintas, eliminando a necessidade de geração de viagens. Na primeira fase, todas as 
jornadas viáveis são geradas a partir dos voos. Na segunda fase, as jornadas são atribuídas aos tripulantes, levando em conta a cobertura de todos os voos e as restrições do problema. Os autores formularam o PPT como um modelo de programação linear inteira de grande escala, o qual incorpora aspectos das regulamentações, acordos coletivos e disponibilidade dos tripulantes, em substituição aos modelos de particionamento e de cobertura de conjuntos. Com isso, a quantidade de variáveis do PPT é reduzida, já que o número de jornadas viáveis enumeradas é sempre da mesma ordem de grandeza que o número de voos, o que possibilita a sua enumeração completa em instâncias reais.

Zeghal e Minoux (2006) destacaram que o modelo proposto considera apenas as regras e regulamentações aplicáveis ao contexto operacional da empresa TunisAir, porém novas restrições podem ser acrescentadas, o que evidentemente aumentaria a complexidade de solução integrada do PPT por métodos exatos.

O modelo foi resolvido através do CPLEX 6.0.2, considerando 20 problemas reais da TunisAir (com no máximo 210 voos e 289 jornadas). Visto que uma solução inteira viável não foi obtida em alguns problemas (após 8 horas de processamento), os autores propuseram uma heurística, em substituição ao CPLEX, baseada em uma estratégia de arredondamento incorporada a um procedimento de busca em árvore, em que uma solução inteira viável foi obtida em todos os problemas (com tempo de processamento inferior a 47 minutos).

Souai e Teghem (2009) adotaram uma estratégia similar à apresentada por Zeghal e Minoux (2006). Na primeira fase, todas as jornadas viáveis são geradas, mas na segunda fase a atribuição de jornadas aos tripulantes é otimizada através de um algoritmo genético híbrido. Neste algoritmo genético híbrido, os operadores de cruzamento e mutação são aplicados de forma alternada. Além disso, duas heurísticas de busca local são utilizadas no refinamento das soluções.

\section{METODOLOGIA PROPOSTA}

A metodologia proposta para solução integrada do PPT, embora inspirada nas abordagens de Zeghal e Minoux (2006) e de Souai e Teghem (2009), incorpora restrições específicas da legislação brasileira e novos mecanismos na geração da população inicial, na estratégia de cruzamento, e na heurística de busca local.

Inicialmente, todas as jornadas viáveis são formadas através de um procedimento de busca em profundidade aplicado a uma rede de voos. Em seguida, um Algoritmo Genético Híbrido $(\mathrm{AGH})$ é utilizado para determinar a melhor combinação de jornadas aos tripulantes a partir de uma solução inicial obtida com o auxílio de um modelo de programação linear inteira, considerando as regras e regulamentações, a disponibilidade dos tripulantes, a cobertura de todos os voos exatamente uma vez, o balanceamento das horas de voo entre os tripulantes, e a minimização do custo total da tripulação.

\subsection{Geração das jornadas}

As jornadas viáveis são geradas através de um procedimento de busca em profundidade aplicado a uma rede de voos. Na rede de voos, $G=(N, A)$, os nós $i \in N$ representam os voos, havendo ainda um nó de origem $s \in N$ e um nó de destino $t \in N$. Os $\operatorname{arcos}(i, j) \in A$ representam as conexões viáveis entre os voos. O nó de origem $s$ possui um arco incidente $(s, i) \in A$ em cada nó $i \in N$. O nó de destino $t$ recebe um arco incidente $(i, t) \in A$ de cada nó $i \in N$.

Um par de voos possui um arco entre eles se o aeroporto de chegada do primeiro voo coincidir com o aeroporto de partida do segundo voo e o intervalo entre os dois voos corresponder a uma conexão viável (considerando o intervalo previsto entre minsit e maxsit) dentro de uma jornada. $\mathrm{O}$ procedimento de busca em profundidade inicia-se no nó de origem $s \in N$ (raiz) e explora todas as conexões viáveis ( $i$, $j) \in A$. Os caminhos $s-t$ viáveis na rede de voos representam as jornadas.

O custo de uma jornada é computado através da expressão 1 e equivale ao custo do tempo ocioso do tripulante mais o seu custo de pernoite.

$$
c_{d}=\alpha \times\left[d_{\max }-\left(t_{p}+t v_{d}+t_{e}\right)\right]+c p_{c}
$$

em que,

$c_{d}:$ custo da jornada $d$;

$\alpha$ : custo do minuto de trabalho de um tripulante;

$d_{\max }$ : duração máxima permitida para uma jornada (em minutos);

$t_{p}:$ tempo de preparação ou brief time (em minutos);

$t v_{d}$ : tempo total de voo da jornada $d$ (em minutos);

$t_{e}$ : tempo de encerramento ou debrief time (em minutos); e

$c p_{c}$ : custo do pernoite na cidade $c$.

\subsection{Algoritmo Genético Híbrido (AGH)}

A estrutura do AGH adotado neste trabalho é apresentada na Figura 1. O critério de parada do AGH considera um número máximo de gerações, dado por Ger_Max, e em cada geração $N$ descendentes são produzidos, onde $N$ é o tamanho da população. Os operadores de cruzamento e mutação são aplicados sequencialmente (e não alternadamente). A mutação é aplicada a um dos descendentes gerados no cruzamento com probabilidade $P m$, e um procedimento de melhoria (busca local) é aplicado ao melhor descendente produzido em cada geração. A atualização da população sobrevivente ocorre no final de cada geração, onde os piores indivíduos são substituídos pelos melhores descendentes.

\subsubsection{Notação adotada}

A notação apresentada abaixo será considerada ao longo deste artigo:

- $J$ : conjunto de dias do horizonte de planejamento considerado $(j \in J)$;

- $F$ : conjunto de voos a ser coberto no horizonte de planejamento $(i \in F)$;

- $K$ : conjunto de tripulantes $(k \in K)$;

- $D$ : conjunto de todas as jornadas viáveis $(d \in D)$ geradas na busca em profundidade;

- $F_{j}$ : conjunto de todos os voos que se iniciam no dia $j \in J\left(F_{j} \subseteq F\right)$;

- $K_{j}$ : conjunto de tripulantes disponíveis para trabalhar no dia $j \in J\left(K_{j} \subseteq K\right)$;

- $D_{j}$ : conjunto de todas as jornadas que se iniciam no $\operatorname{dia} j \in J\left(D_{j} \subseteq D\right)$;

- $\bar{D}_{j}$ : conjunto ótimo de jornadas que se iniciam no 


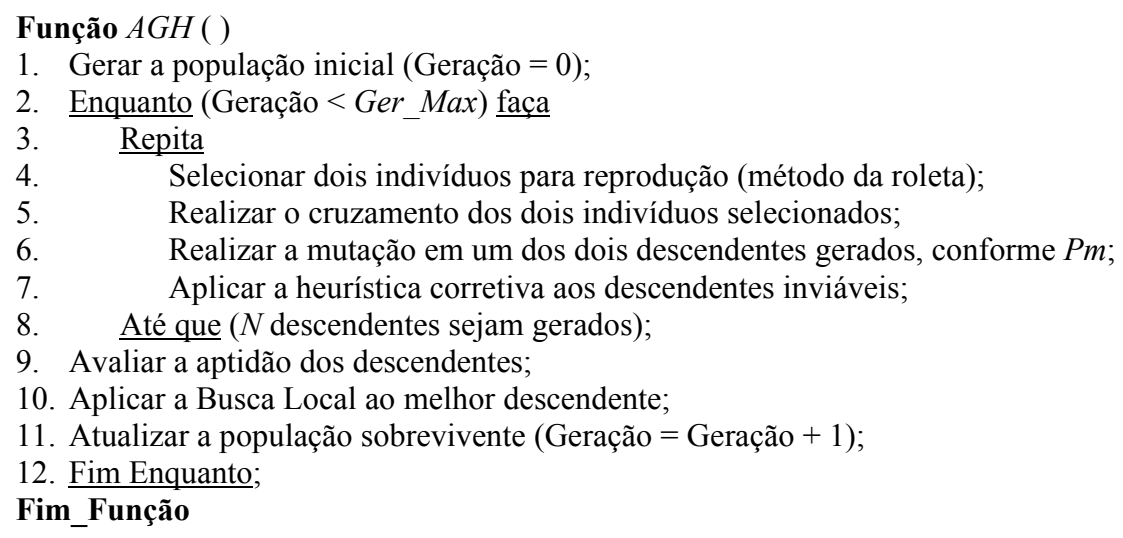

Figura 1. Estrutura do AGH

\begin{tabular}{|c|c|c|c|c|c|c|c|}
\hline & $\mathbf{1}$ & $\mathbf{2}$ & $\mathbf{3}$ & $\mathbf{4}$ & $\mathbf{5}$ & $\mathbf{6}$ & $\mathbf{7}$ \\
\hline $\mathbf{1}$ & -1 & 19 & 22 & 40 & 47 & 0 & -1 \\
\hline $\mathbf{2}$ & 5 & 13 & -1 & 33 & 0 & -1 & 62 \\
\hline $\mathbf{3}$ & 1 & -1 & 21 & 0 & -1 & 50 & 61 \\
\hline $\mathbf{4}$ & 0 & 0 & 0 & -1 & -1 & 0 & 0 \\
\hline
\end{tabular}

Figura 2. Exemplo de um cromossomo

dia $j \in J\left(\bar{D} j \subseteq D_{j}\right)$, ou seja, que cobrem todos os voos $i \in F_{j}$ exatamente uma vez com custo mínimo;

- $D_{j}^{k}$ : conjunto de todas as jornadas que podem ser atribuídas ao tripulante $k$ no dia $j$, isto é, que satisfazem a todas as regras e regulamentações;

- $F_{d j}$ : conjunto de voos cobertos pela jornada $d \in D_{j}$ no $\operatorname{dia} j \in J$;

- $F n c_{n j}$ : conjunto de voos não cobertos pelo indivíduo (solução) $n$ no dia $j \in J$;

- $F S c_{n j}$ : conjunto de voos sobre-cobertos pelo indivíduo (solução) $n$ no dia $j \in J$;

- $P e n a_{n j}$ : penalidade do indivíduo $n$ relacionada aos voos não cobertos e aos voos sobre-cobertos no dia $j \in J$, dada por $P e n a_{n j}=\left|F n c_{n j}\right|+\left|F s c_{n j}\right|$;

- $P e n a_{n j}$ : penalidade do indivíduo $n$ relacionada aos voos não cobertos e aos voos sobre-cobertos, dada por Pena $_{n}=\sum_{j \in J}$ Pena $_{n j}$.

\subsubsection{Codificação do cromossomo}

O cromossomo é representado por uma matriz $X=\left(x_{k j}\right)_{|K| \times J \mid}$. Um gene $x_{k j}$ recebe o valor 0 se nenhuma jornada for atribuída ao tripulante $k$ no dia $j$ (dia livre), o valor -1 se o tripulante $k$ estiver indisponível para trabalhar no dia $j$, isto é, se ao tripulante $k$ no dia $j$ foi pré-atribuída outra atividade (como folga, treinamento, reunião, exame periódico, entre outras), ou um valor $d$ (inteiro e positivo) que representa o código associado à jornada $d \in D_{j}$ atribuída ao tripulante $k$ no dia $j$.

A Figura 2 ilustra um cromossomo com $|K|=4$ e
$|J|=7$. Neste exemplo, ao tripulante 1 foram atribuídas as jornadas 19, 22, 40 e 47 nos dias 2, 3, 4 e 5, respectivamente. Além disso, o tripulante 1 está indisponível para trabalhar nos dias 1 e 7, e está livre para receber uma jornada no dia 6. Em contrapartida, o tripulante 4 não foi utilizado nesta solução.

O custo de um cromossomo (solução ou indivíduo) $n$ é computado através da expressão 2 .

$$
C_{n}=\sum_{k \in K} c_{k} y_{k}
$$

em que,

$C_{n}$ : custo do cromossomo $n$;

$c_{k}$ : custo das jornadas atribuídas ao tripulante $k$ (escala);

$y_{k}$ : igual a 1 se o tripulante $k$ for utilizado na solução $n$, e zero caso contrário.

O custo das jornadas atribuídas a cada tripulante $k \in K$ é computado através da expressão 3 .

$$
c_{k}=\alpha_{1}+\max \left\{0,\left(\sum_{d \in D_{k}} t v_{d}\right)-M G\right\} \times \alpha_{2}+\sum_{d \in D_{k}} c_{d}
$$

sendo,

$\alpha_{1}$ : salário fixo de um tripulante;

$D_{k}$ : conjunto de jornadas atribuídas ao tripulante $k$;

$t v_{d}$ : tempo total de voo da jornada $d$;

$M G$ : tempo de voo computado no salário fixo de um tripulante (garantia mínima);

$\alpha_{2}$ : salário por hora de voo excedente à garantia mínima;

$c_{d}$ : custo da jornada $d$. 


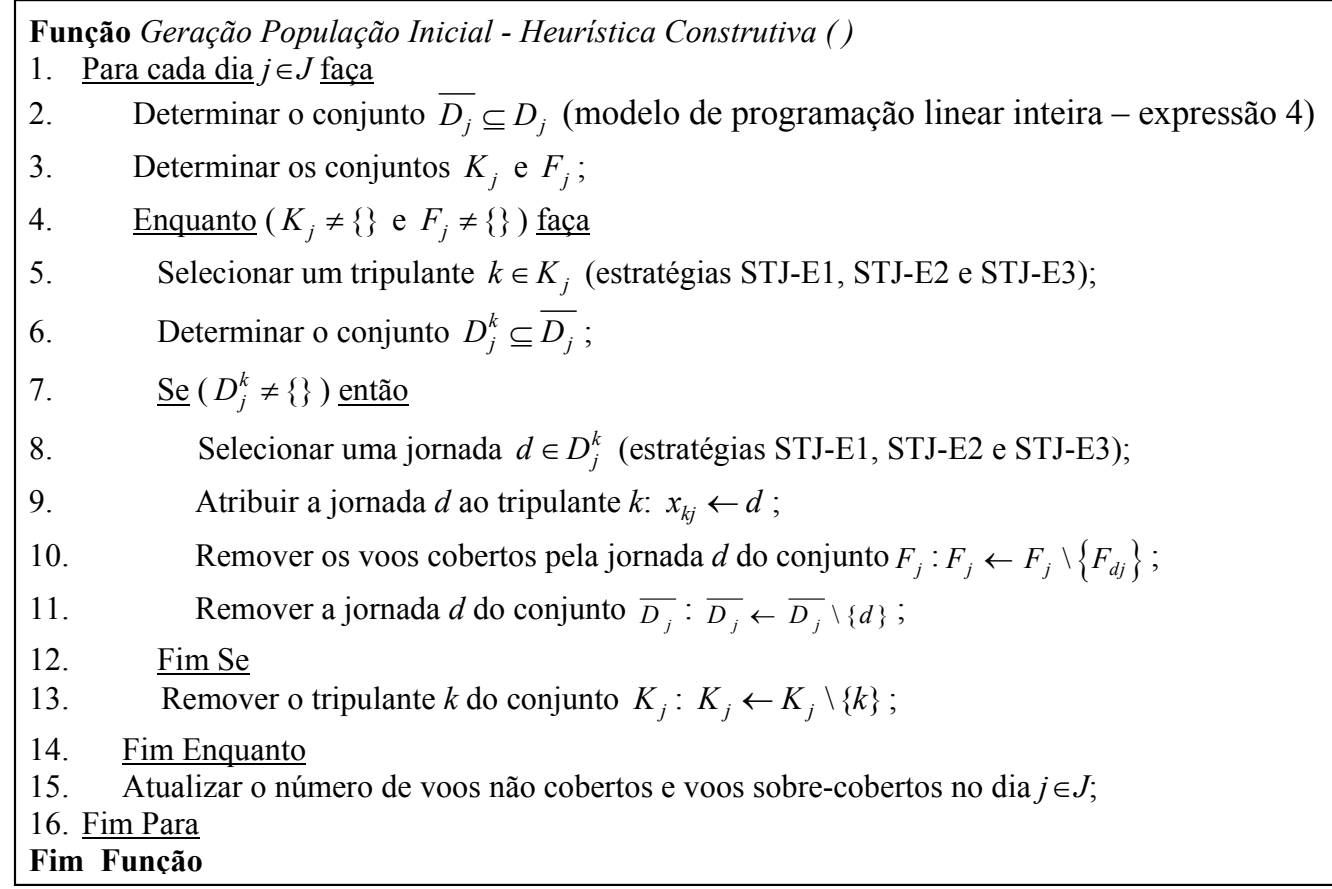

Figura 3. Geração da população inicial (heurística construtiva)

\subsubsection{População inicial}

A população inicial (de $N$ indivíduos) é gerada através de uma heurística construtiva, cujo pseudocódigo é apresentado na Figura 3.

Para cada dia $j \in J$, um conjunto ótimo de jornadas $\overline{D_{j}} \subseteq D_{j}$ (linha 2 da Figura 3 ) que cubra todos os voos $i \in F_{j}$ exatamente uma vez é determinado. Para este propósito, um modelo de programação linear inteira, baseado no problema de particionamento de conjuntos, foi considerado, a saber:

$$
\overline{D_{j}}=\left\{\begin{array}{l}
\operatorname{Min} \sum_{d \in D_{j}} c_{d} y_{d} \\
s . a . \\
\sum_{d \in D_{j}} a_{i d} y_{d}=1 \quad \forall i \in F_{j} \\
y_{d} \in\{0,1\} \quad \forall d \in D_{j}
\end{array}\right\}
$$

em que,

$a_{i d}$ : igual a 1 se o voo $i$ for coberto pela jornada $d$, e zero caso contrário;

$y_{d}$ : igual a 1 se a jornada $d$ for incluída no conjunto $\overline{D_{j}}$, e zero caso contrário.

A função objetivo visa à minimização do número de jornadas selecionadas, ou seja, do número de tripulantes necessários para a cobertura de todos os voos $i \in F_{j}$.

Em seguida, as jornadas do conjunto $\overline{D_{j}}$ são atribuídas aos tripulantes ( $k \in K_{j}$ ) disponíveis no dia $j$ iterativamente, piloto a piloto, assegurando a satisfação de todas as regras e regulamentações. Neste ponto, a ordem de seleção dos tripulantes (linha 5 da Figura 3) e a ordem de seleção das jornadas (linha 8 da Figura 3) influenciam no balanceamento da distribuição de horas de voo entre os tripulantes, conforme observado em Cabral et al. (2000). Assim sendo, três estratégias distintas para seleção dos tripulantes e das jornadas foram consideradas: STJ-E1, STJ-E2 e STJ-E3.

A estratégia STJ-E1 segue a abordagem proposta por Souai e Teghem (2009), onde, em cada iteração, um tripulante $k \in K_{j}$ selecionado aleatoriamente recebe a jornada $d \in D_{j}^{k}$ que cobre o maior número de voos $i \in F_{j}$.

Na estratégia STJ-E2, os tripulantes $k \in K_{j}$ são, inicialmente, classificados em ordem crescente de prioridade de atribuição e de horas de voo acumuladas, e, posteriormente, são selecionados sequencialmente para atribuição das jornadas $d \in D_{j}^{k}$ selecionadas aleatoriamente.

Para tanto, os tripulantes $k \in K_{j}$ são classificados por ordem crescente de prioridade de atribuição (linha 3 da Figura 3), considerando dois grupos: primeiro, os tripulantes que já receberam alguma jornada na solução; e, segundo, os tripulantes não utilizados na solução. Em seguida, os tripulantes de cada grupo são reclassificados em ordem crescente de horas de voo acumuladas. Com isso, a estratégia STJE2 visa a reduzir tanto o desbalanceamento da distribuição de horas de voo entre os tripulantes quanto o número de tripulantes utilizados na solução.

Na estratégia STJ-E3, a seleção dos tripulantes ocorre como na estratégia STJ-E2. Já a seleção das jornadas segue um procedimento baseado na fase de construção da metaheurística GRASP, proposta por Feo e Resende (1995). Neste caso, em cada iteração, determina-se o conjunto $D_{j}^{k}$ (linha 6 da Figura 3) para o tripulante $k$ selecionado (linha 5 da Figura 3); em seguida, constrói-se uma lista restrita de candidatos (LRC) com as $p$ jornadas do conjunto $D_{j}^{k}$ que cobrem o maior número de voos $i \in F_{j}$, em que 
$p=\left|D_{j}^{k}\right| / 2$; por fim, uma jornada $d \in L R C$ a ser atribuída ao tripulante $k$ é selecionada aleatoriamente.

A heurística construtiva não garante a cobertura de todos os voos e, em alguns casos, os tripulantes podem voar como passageiros em uma jornada. Este tipo de voo é denominado deadhead. O deadhead é normalmente utilizado para reposicionar um tripulante em determinada cidade, ou para permitir o retorno de um tripulante à sua base domiciliar no final de uma jornada. Dessa forma, a aptidão de um indivíduo $n$ com $P e n a_{n}>0$, isto é, com voos não cobertos ou sobre-cobertos (deadheads), é penalizada (vide Seção 3.2.4 a seguir).

\subsubsection{Função de avaliação da aptidão}

A função de avaliação da aptidão (Fitness) mede a qualidade de cada indivíduo da população. Os indivíduos com maior aptidão ou qualidade são selecionados para a recombinação e sobrevivência. A aptidão de um indivíduo $n$ é definida através da expressão 5, proposta por Souai e Teghem (2009).

$$
F A_{n}=\frac{C T_{\max }-C T_{n}}{C T_{\max }}
$$

em que,

$F A_{n}$ : função de aptidão do indivíduo $n$, onde $F A_{n} \in[0,1]$;

$C T_{n}$ : custo total do indivíduo $n$;

$C T_{\max }$ : maior custo total da população corrente.

O custo total de um indivíduo $n$ leva em conta a penalidade relacionada aos voos não cobertos e aos voos sobrecobertos, o custo do indivíduo $n$ (expressão 2) e o balanceamento da distribuição de horas de voo entre os tripulantes.

A expressão 6, adaptada de Souai e Teghem (2009), é utilizada para calcular o custo total de cada indivíduo da população corrente.

$$
C T_{n}=\beta_{1} \times \text { Pena }_{n}+\beta_{2} \times C_{n}+\sigma_{n}
$$

em que,

$C T_{n}$ : custo total do indivíduo $n$;

Pena $_{n}$ : penalidade do indivíduo $n$ relacionada aos voos não cobertos ou sobre-cobertos;

$C_{n}$ : custo do indivíduo $n$

$\sigma_{n}$ : desvio-padrão das horas de voo do indivíduo $n$.

Os parâmetros $\beta_{1}$ e $\beta_{2}$ devem ser definidos de forma adequada para minimizar hierarquicamente os três termos da expressão 6 , ou seja, primeiro, a penalidade relacionada a não cobertura ou sobre-cobertura dos voos; a seguir, o custo dos tripulantes; e, por fim, o desvio-padrão das horas de voo.

$\mathrm{O}$ valor do parâmetro $\beta_{1}$ deve assegurar que $\beta_{1} \times P e n a_{n}$
$>C_{n}, \forall n$. Com isso, $\beta_{1}$ é calculado da seguinte forma: primeiro, o custo de uma jornada inativa é determinado, isto é, o custo de uma jornada em que o tripulante não voa; em seguida, uma solução inviável é gerada, em que a jornada inativa é atribuída a todos os tripulantes $k \in K$, em cada dia $j \in J$, supondo que não há dias livres; e, finalmente, o valor de $\beta_{1}$ é definido por:

$$
\beta_{1}=c_{\max } \times|K|
$$

em que,

$c_{\max }$ : custo máximo da escala inviável (limite superior) atribuída a um tripulante $k \cdot c_{\max }=\alpha_{1}+c_{d} \times|J|$

$\mathrm{O}$ valor de $\beta_{2}$ é determinado através da expressão 8:

$$
\beta_{2}= \begin{cases}\frac{A+B}{2} & \text { se } A \neq 0 \\ B & \text { se } A=0\end{cases}
$$

em que,

$$
A=\min _{n=1, \ldots, N \text { s.a. } C_{n} \neq 0}\left\{\frac{\beta_{1} \times \text { Pena }_{n}}{C_{n}}\right\} \text { e } B=\max _{n=1, \ldots, N \text { s.a. } C_{n} \neq 0}\left\{\frac{\sigma_{n}}{C_{n}}\right\} .
$$

\subsubsection{Cruzamento e mutação}

O operador de cruzamento recombina as informações genéticas (genes $x_{k j}$ ) dos indivíduos $X$ e $Y$ (pais) selecionados através do método da roleta, a fim de se obter dois novos indivíduos $X^{\prime}$ e $Y^{\prime}$ (descendentes). Para tanto, quatro estratégias de cruzamento são consideradas: CS-MP (Cruzamento Simplificado em Múltiplos Pontos) e CP-MP (Cruzamento Probabilístico em Múltiplos Pontos), propostas por Souai e Teghem (2009); CA-MP (Cruzamento Aleatório em Múltiplos Pontos), adaptada de Souai e Teghem (2009); e CA-UP (Cruzamento Aleatório em um Único Ponto), proposta por Chang (2002).

$\mathrm{Na}$ estratégia CS-MP (Figura 4), um número $n$ é determinado aleatoriamente, com $1 \leq n \leq \min \{|K|,|J|\}$. Em seguida, $n$ genes distintos são selecionados aleatoriamente, de tal forma que não sejam selecionados dois genes na mesma linha $k \in K$ ou na mesma coluna $j \in J$. Por fim, somente os $n$ genes selecionados são trocados entre os pais $X$ e $Y$, gerando os descendentes $X^{\prime}$ e $Y^{\prime}$.

Na estratégia CP-MP (Figura 4), a seleção aleatória de $n$ genes distintos é realizada como na estratégia CS-MP. Em seguida, os genes selecionados que não inviabilizam as soluções $X^{\prime}$ e $Y^{\prime}$ são trocados automaticamente. Para os demais genes selecionados, a troca dependerá do grau de inviabilidade das soluções, mensurado através da penalidade do dia $j$. Mais precisamente (por exemplo, na solução $X^{\prime}$ ), se $P e n a_{X^{\prime}} \leq P e n a_{X j}$, então a troca é efetuada; caso
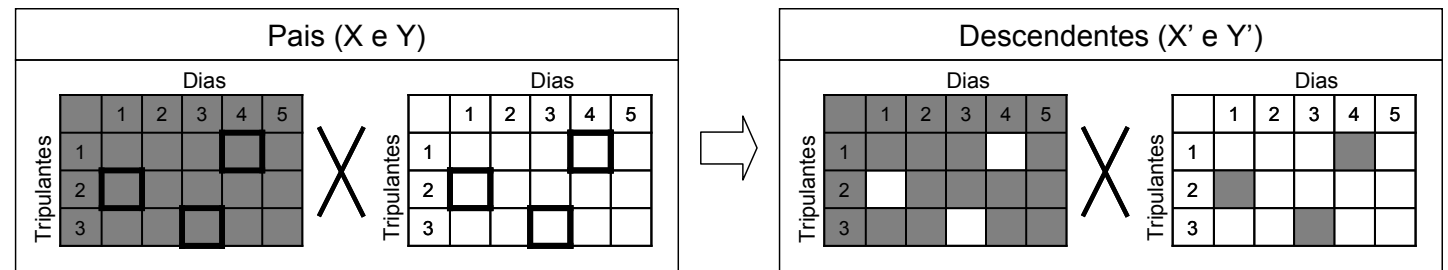

Figura 4. Operadores CS-MP e CP-MP 

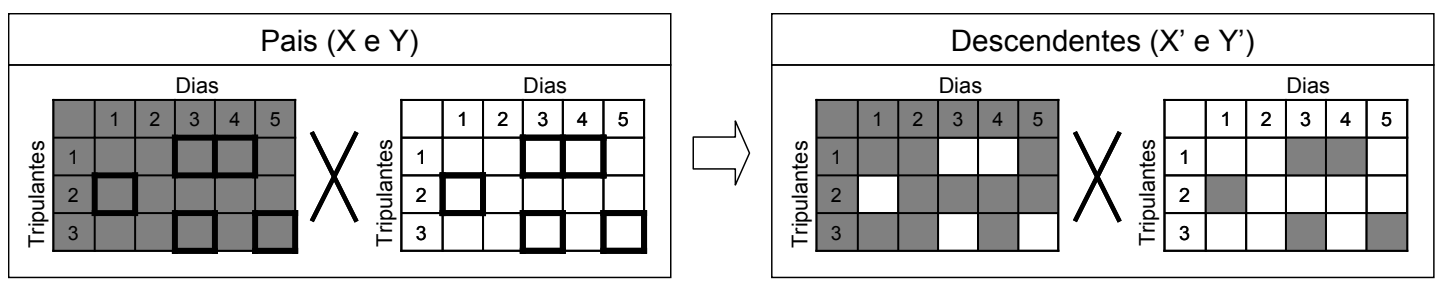

Figura 5. Operador CA-MP
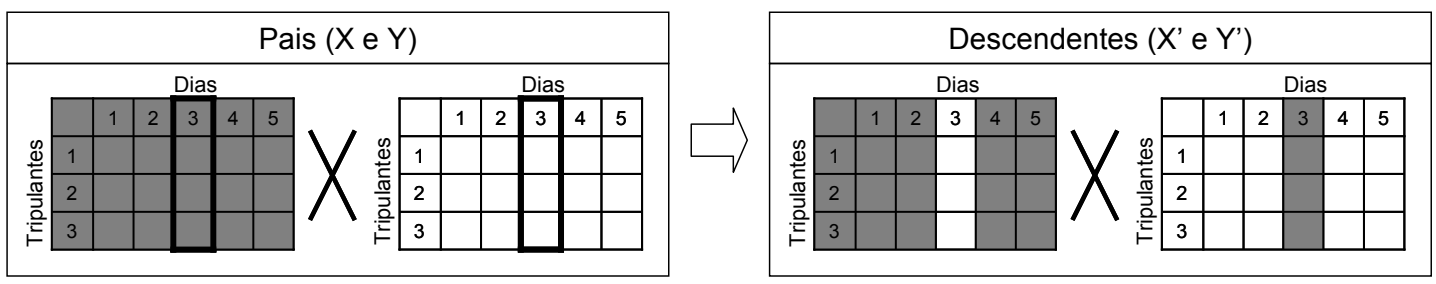

Figura 6. Operador CA-UP

contrário, a troca é efetuada conforme a probabilidade $P$ definida por $P=\frac{1}{P e n a_{X^{\prime} j}-P e n a_{X j}+1}$.

Embora Souai e Teghem (2009) não explicitaram que os $n$ genes distintos selecionados nas estratégias CS-MP e CPMP possuem valores diferentes de -1 , adotou-se, nesta pesquisa, que todos os genes selecionados em ambas as estratégias devem ser tais que $x_{k j} \neq-1$, evitando assim uma operação de troca desnecessária.

$\mathrm{Na}$ estratégia CA-MP (Figura 5), um número $n$ é determinado aleatoriamente, com $1 \leq n \leq \max \{|K|,|J|\}$. Em seguida, $n$ genes distintos são selecionados aleatoriamente, onde $x_{k j} \neq-1$ para todo gene selecionado. Por fim, os $n$ genes são trocados entre os pais $X$ e $Y$. Nesta estratégia, ao contrário da estratégia CS-MP, dois genes podem ser selecionados na mesma linha $k \in K$, ou na mesma coluna $j \in J$.

Na estratégia CA-UP (Figura 6), um dia $j \in J$ é selecionado aleatoriamente. Em seguida, os genes deste dia são trocados automaticamente entre os pais $X$ e $Y$.

O operador de mutação é aplicado com probabilidade $P m$ a um dos dois descendentes $X^{\prime}$ e $Y^{\prime}$ gerados no cruzamento. No início, seleciona-se aleatoriamente um descendente ( $X^{\prime}$ ou $Y^{\prime}$ ), um dia $j \in J$ e dois tripulantes $k$ e $k^{\prime}$ do conjunto $K$, onde $x_{k j} \neq-1$ e $x_{k^{\prime} j} \neq-1$. Em seguida, os genes $x_{k j}$ e $x_{k^{\prime} j}$ são trocados.

\subsubsection{Heurística Corretiva}

A heurística corretiva é aplicada aos descendentes inviáveis ( $X^{\prime}$ e $Y^{\prime}$ ) gerados após o cruzamento ou a mutação, visando à correção dos genes $x_{k j}^{\prime}$ com atribuições que não satisfazem a todas as restrições.

Neste caso, iterativamente, para cada gene $x_{k j}^{\prime}$ inviável, constrói-se o conjunto de jornadas $D_{j}^{k}$ que podem ser atribuídas ao tripulante $k$ no dia $j$, isto é, que satisfazem a todas as restrições. Se o conjunto $D_{j}^{k} \neq\{\}$ então determina-se um conjunto de voos $F_{h c}$ a ser coberto na heurística corretiva. Se $F_{h c} \neq\{\}$ então atribui-se ao tripulante $k$ a jornada $d \in D_{j}^{k}$ que cobre o maior número de voos $i \in F_{h c}$ e o menor número de voos $i \notin F_{h c}$, reduzindo a penalidade do indivíduo $n$ relacionada aos voos não cobertos e aos voos sobrecobertos no dia $j$. Caso contrário, $\left(F_{h c}=\{\}\right)$, todos os voos $i \in F_{h c}$ estão cobertos e o gene $x_{k j}^{\prime}$ é igual a zero $\left(x_{k j}^{\prime}=0\right)$. Com isso, atribui-se ao tripulante $k$ a jornada $d \in D_{j}^{k}$ que cobre o menor número de voos $i \in F_{j}$, reduzindo a penalidade do indivíduo $n$ relacionada aos voos sobre-cobertos no dia $j$.

Quando uma jornada viável $d \in D_{j}^{k}$ não é identificada na heurística corretiva ( $D_{j}^{k}=\{\}$ ), o gene $x_{k j}$ removido durante o cruzamento ou a mutação é restaurado. Por exemplo, $x_{k j}^{\prime} \leftarrow x_{k j}$, em que $x_{k j}^{\prime}$ é um gene inviável do descendente $X^{\prime}$ e $x_{k j}$ é um gene viável do pai $X$. Com isso, a viabilidade da solução é garantida ao término da heurística corretiva.

\subsubsection{Busca Local}

A busca local tradicional, também conhecida como busca em vizinhança, é um procedimento de melhoria no qual a vizinhança $N(x *) \subseteq X$ (onde $X$ denota o espaço de soluções viáveis) da solução corrente $x *$ é explorada iterativamente até que uma solução vizinha $x^{\prime} \in N\left(x^{*}\right)$ melhor do que $x *$ não seja obtida (Cunha, 2006).

No AGH é aplicada uma busca local simplificada. Neste contexto, em cada geração, dado o melhor descendente (solução $\left.x^{*}\right)$, exploram-se somente duas soluções vizinhas $x^{\prime} \in N\left(x^{*}\right)$, obtidas através de dois tipos de movimentos distintos: movimento de reatribuição e movimento de troca. Se uma das duas soluções vizinhas $x^{\prime}$ (uma para cada movimento) for melhor do que a solução $x^{*}$, substitui-se $x^{*}$ por $x^{\prime}\left(x^{*} \leftarrow x^{\prime}\right)$. Tal simplificação é adotada para evitar que o procedimento de busca local reduza a eficiência do AGH.

O movimento de reatribuição consiste em remover uma jornada atribuída a um dado tripulante e, em seguida, reatribuí-la a outro tripulante disponível no mesmo dia. O movimento de troca consiste em trocar as jornadas atribuídas a 
Tabela 1. Instâncias de teste

\begin{tabular}{lllll}
\hline Instância & Aeronave & $\boldsymbol{N}^{\boldsymbol{o}}$ de Voos & Horizonte de Planejamento (em dias) & Período de Abrangência \\
\hline MA1 & Embraer 120 (Turboélice) & 208 & 14 & $06 / 04 / 2008$ a 19/04/2008 \\
\hline MA2 & Embraer 120 (Turboélice) & 416 & 28 & $01 / 06 / 2008$ a 28/06/2008 \\
\hline
\end{tabular}

Tabela 2. Resultados obtidos na etapa de geração das jornadas

\begin{tabular}{lccccc}
\hline & $\boldsymbol{N}^{\boldsymbol{o}}$ de & \multicolumn{2}{c}{ Rede de Voos } & \multicolumn{2}{c}{ Geração das Jornadas } \\
\cline { 3 - 6 } Instância & Voos & Nós & Arcos & $N^{o}$ de Jornadas & Tempo $(s)$ \\
\hline MA1 & 208 & 210 & 620 & 868 & $<1$ \\
MA2 & 416 & 418 & 1.240 & 1.736 & $<1$ \\
\hline
\end{tabular}

Tabela 3. Resultados obtidos no AGH para a instância MA1

\begin{tabular}{|c|c|c|c|c|c|c|c|c|c|}
\hline $\begin{array}{l}\text { População } \\
\text { Inicial }\end{array}$ & $\begin{array}{l}\text { Estratégia de } \\
\text { Cruzamento }\end{array}$ & $\begin{array}{l}\boldsymbol{C T} \\
\left(C T_{n}\right) \\
\end{array}$ & $\begin{array}{l}\text { Penalidade } \\
\left(\text { Pena }_{n}\right)\end{array}$ & $\begin{array}{l}\text { Custo } \\
\left(C_{n}\right)\end{array}$ & $\begin{array}{l}\text { Desvio- } \\
\text { Padrão } \\
\left(\sigma_{n}\right)\end{array}$ & $\begin{array}{l}N^{o} \text { de } \\
\text { Tripulantes }\end{array}$ & Geração & $\begin{array}{l}\text { Tempo } \\
\text { (s) }\end{array}$ & $\begin{array}{l}\text { Desvio CT } \\
\text { (\%) }\end{array}$ \\
\hline \multirow{4}{*}{ STJ-E1 } & CS-MP & 224,93 & 0 & 98.520 & 33,41 & 10 & 50.000 & 211 & $53,36 \%$ \\
\hline & CP-MP & 208,00 & 0 & 96.250 & 20,88 & 10 & 50.000 & 178 & $41,82 \%$ \\
\hline & CA-MP & 203,31 & 0 & 97.020 & 14,69 & 10 & 10.000 & 56 & $38,62 \%$ \\
\hline & CA-UP & 207,96 & 0 & 97.830 & 17,77 & 10 & 30.000 & 94 & $41,79 \%$ \\
\hline \multirow{4}{*}{ STJ-E2 } & CS-MP & 188,84 & 0 & 69.950 & 52,85 & 8 & 50.000 & 246 & $28,75 \%$ \\
\hline & CP-MP & 192,37 & 0 & 85.712 & 25,74 & 9 & 30.000 & 104 & $31,16 \%$ \\
\hline & CA-MP & 155,69 & 0 & 67.035 & 25,37 & 8 & 10.000 & 57 & $6,15 \%$ \\
\hline & CA-UP & 174,56 & 0 & 83.325 & 12,57 & 9 & 40.000 & 122 & $19,02 \%$ \\
\hline \multirow{4}{*}{ STJ-E3 } & CS-MP & 193,61 & 0 & 70.520 & 56,51 & 8 & 50.000 & 230 & $32,00 \%$ \\
\hline & CP-MP & 168,62 & 0 & 70.520 & 31,52 & 8 & 50.000 & 192 & $14,97 \%$ \\
\hline & СА-МP & 146,67 & 0 & 69.280 & 11,98 & 8 & 50.000 & 263 & $0,00 \%$ \\
\hline & CA-UP & 148,82 & 0 & 68.120 & 16,39 & 8 & 20.000 & 68 & $1,47 \%$ \\
\hline
\end{tabular}

$\beta_{1}=216.000$ e $\beta_{2}=0,001944$

dois tripulantes no mesmo dia.

Em ambos os movimentos, a escolha dos dias, dos tripulantes e das jornadas é aleatória.

\section{TESTES E APLICAÇÕES PRÁTICAS}

A metodologia proposta foi testada para solução de duas instâncias do PPT associadas à operação de uma empresa da aviação regional brasileira, levando em conta a programação dos tripulantes técnicos (pilotos) e a existência de apenas uma base domiciliar. A Tabela 1 sumariza as instâncias de teste.

Os parâmetros utilizados para calcular o custo das jornadas (expressão 1) e o custo das escalas (expressão 3) foram: $\alpha=2, d_{\max }=660 \mathrm{~min}, t_{p}=30 \mathrm{~min}, t_{e}=30 \mathrm{~min}, c p_{c}=200$, $\alpha_{1}=2.000, M G=54 \mathrm{~h} \mathrm{e} \alpha_{2}=10$.

$\mathrm{O}$ procedimento de busca em profundidade e o AGH foram implementados na linguagem $\mathrm{C}++$ e testados em um microcomputador PC Intel Core 2 Quad, 2,40 Ghz, com 2 GB de RAM, sob o sistema operacional Microsoft Windows XP (Professional). O modelo matemático utilizado na geração da população inicial (Seção 3.2.3) foi resolvido através do pacote de programação linear ILOG CPLEX 11.0.

A Tabela 2 apresenta os resultados obtidos na etapa de geração das jornadas (Seção 3.1). Os tempos de processamento foram inferiores a 1 segundo.

As Tabelas 3 e 4 apresentam os melhores resultados obtidos no AGH (Seção 3.2) para as instâncias MA1 e MA2, respectivamente, após cinco execuções independentes, levando em conta um número máximo de 50.000 gerações (Ger Max), uma população de 200 indivíduos (após comparação com 100 e 300 indivíduos) e uma probabilidade de mutação $P m=0,3 \%$ (após comparação com $0,1 \%, 0,5 \%$, $0,7 \%$ e $1 \%)$.

Nestas tabelas, a primeira e a segunda coluna apresentam a estratégia adotada na heurística construtiva para geração da população inicial (Seção 3.2.3) e no cruzamento (Seção 3.2.5), respectivamente. As colunas seguintes contêm, respectivamente, o custo total da melhor solução (expressão 6), a penalidade relacionada aos voos não cobertos e sobrecobertos, o custo associado à utilização dos tripulantes, o desvio-padrão das horas de voos atribuídas aos tripulantes, o número de tripulantes utilizados na solução, o número da geração em que a solução foi obtida, o tempo de processamento (em segundos) e o desvio percentual do custo total em relação à melhor solução. Os valores dos parâmetros $\beta_{1}$ e $\beta_{2}$ são apresentados no rodapé das tabelas.

É possível observar que a estratégia STJ-E3 (seleção determinística dos tripulantes e seleção aleatória das jornadas em uma lista restrita de candidatos), combinada com o cruzamento aleatório em múltiplos pontos (CA-MP), produziu a melhor solução final em ambas as instâncias (MA1 e MA2). Em contrapartida, as piores soluções foram obtidas com a estratégia STJ-E1 (seleção aleatória dos tripulantes e seleção determinística das jornadas), proposta por Souai e Teghem (2009).

A Tabela 5 apresenta a variação do custo total das soluções obtidas nas cinco execuções independentes do AGH. As colunas desta tabela contêm, respectivamente, a instância de teste, a estratégia de geração da população inicial, a estratégia de cruzamento, o custo total mínimo, o custo total médio, o custo total máximo e a variação percentual entre o custo total médio e o custo total mínimo. 
Tabela 4. Resultados obtidos no AGH para a instância MA2

\begin{tabular}{|c|c|c|c|c|c|c|c|c|c|}
\hline $\begin{array}{l}\text { População } \\
\text { Inicial }\end{array}$ & $\begin{array}{l}\text { Estratégia de } \\
\text { Cruzamento }\end{array}$ & $\begin{array}{l}C \boldsymbol{T} \\
\left(C T_{n}\right) \\
\end{array}$ & $\begin{array}{l}\text { Penalidade } \\
\left(\text { Pena }_{n}\right)\end{array}$ & $\begin{array}{l}\text { Custo } \\
\left(C_{n}\right) \\
\end{array}$ & $\begin{array}{l}\text { Desvio- } \\
\text { Padrão } \\
\left(\sigma_{n}\right)\end{array}$ & $\begin{array}{l}N^{o} \text { de Tri- } \\
\text { pulantes }\end{array}$ & Geração & $\begin{array}{l}\text { Tem- } \\
\text { po }(s)\end{array}$ & $\begin{array}{l}\text { Desvio } \\
C T(\%)\end{array}$ \\
\hline \multirow{4}{*}{ STJ-E1 } & CS-MP & 294,19 & 0 & 177.040 & 10,20 & 10 & 50.000 & 305 & $31,91 \%$ \\
\hline & CP-MP & 307,36 & 0 & 177.610 & 22,45 & 10 & 40.000 & 200 & $37,81 \%$ \\
\hline & CA-MP & 295,11 & 0 & 177.610 & 10,20 & 10 & 10.000 & 115 & $32,32 \%$ \\
\hline & CA-UP & 292,34 & 0 & 174.760 & 12,00 & 10 & 30.000 & 141 & $31,08 \%$ \\
\hline \multirow{4}{*}{ STJ-E2 } & CS-MP & 266,45 & 0 & 145.405 & 33,20 & 9 & 50.000 & 281 & $19,47 \%$ \\
\hline & CP-MP & 266,77 & 0 & 153.362 & 20,76 & 9 & 30.000 & 148 & $19,61 \%$ \\
\hline & CA-MP & 252,37 & 0 & 150.470 & 11,00 & 9 & 30.000 & 322 & $13,16 \%$ \\
\hline & CA-UP & 253,24 & 0 & 149.330 & 13,70 & 9 & 30.000 & 129 & $13,55 \%$ \\
\hline \multirow{4}{*}{ STJ-E3 } & CS-MP & 243,93 & 0 & 127.320 & 39,69 & 8 & 20.000 & 160 & $9,37 \%$ \\
\hline & CP-MP & 242,39 & 0 & 127.362 & 38,08 & 8 & 30.000 & 144 & $8,68 \%$ \\
\hline & CA-MP & 223,03 & $\mathbf{0}$ & 122.540 & 26,46 & 8 & 40.000 & 459 & $0,00 \%$ \\
\hline & CA-UP & 235,77 & 0 & 125.610 & 34,28 & 8 & 20.000 & 86 & $5,71 \%$ \\
\hline
\end{tabular}

Tabela 5. Variação do custo total das soluções obtidas no AGH

\begin{tabular}{|c|c|c|c|c|c|c|}
\hline \multirow[b]{2}{*}{ Instância } & \multirow[b]{2}{*}{$\begin{array}{l}\text { População } \\
\text { Inicial }\end{array}$} & \multirow[b]{2}{*}{$\begin{array}{l}\text { Estratégia } \\
\text { de Cruzamento }\end{array}$} & \multicolumn{3}{|l|}{$C T$} & \multirow[b]{2}{*}{ Variação (\%) } \\
\hline & & & $\begin{array}{l}\text { Mínimo } \\
\left(C T_{\min }\right)\end{array}$ & $\begin{array}{l}\text { Médio } \\
\left(C T_{\text {med }}\right)\end{array}$ & $\begin{array}{l}\text { Máximo } \\
\left(C T_{\max }\right)\end{array}$ & \\
\hline \multirow{12}{*}{ MA1 } & & CS-MP & 224,93 & 227,31 & 228,56 & $1,06 \%$ \\
\hline & & CP-MP & 208,00 & 215,30 & 228,53 & $3,51 \%$ \\
\hline & & CA-MP & 203,31 & 210,66 & 223,15 & $3,61 \%$ \\
\hline & STJ-E1 & CA-UP & 207,96 & 218,21 & 223,65 & $4,93 \%$ \\
\hline & & CS-MP & 188,84 & 198,43 & 207,61 & $5,08 \%$ \\
\hline & & CP-MP & 192,37 & 197,47 & 204,89 & $2,65 \%$ \\
\hline & & CA-MP & 155,69 & 172,41 & 200,27 & $10,74 \%$ \\
\hline & STJ-E2 & CA-UP & 174,56 & 189,04 & 204,60 & $8,29 \%$ \\
\hline & & CS-MP & 193,61 & 196,91 & 201,11 & $1,70 \%$ \\
\hline & & CP-MP & 168,62 & 178,28 & 188,06 & $5,73 \%$ \\
\hline & & CA-MP & 146,67 & 153,13 & 159,85 & $4,41 \%$ \\
\hline & STJ-E3 & CA-UP & 148,82 & 160,54 & 170,00 & $7,87 \%$ \\
\hline \multirow{12}{*}{ MA2 } & & CS-MP & 294,19 & 313,91 & 328,26 & $6,70 \%$ \\
\hline & & CP-MP & 307,36 & 315,12 & 324,59 & $2,52 \%$ \\
\hline & & CA-MP & 295,11 & 301,58 & 314,79 & $2,19 \%$ \\
\hline & STJ-E1 & CA-UP & 292,34 & 305,42 & 313,79 & $4,48 \%$ \\
\hline & & CS-MP & 266,45 & $165.105,22$ & $412.317,97^{*}$ & $61.864,10 \%$ \\
\hline & & CP-MP & 266,77 & $247.481,65$ & $412.295,35^{*}$ & $92.669,32 \%$ \\
\hline & & CA-MP & 252,37 & 283,25 & 313,05 & $12,23 \%$ \\
\hline & STJ-E2 & CA-UP & 253,24 & 273,00 & 310,24 & $7,80 \%$ \\
\hline & & CS-MP & 243,93 & 247,90 & 256,92 & $1,63 \%$ \\
\hline & & CP-MP & 242,39 & 253,01 & 272,97 & $4,38 \%$ \\
\hline & & CA-MP & 223,03 & 230,92 & 244,36 & $3,54 \%$ \\
\hline & STJ-E3 & CA-UP & 235,77 & 243,07 & 263,57 & $3,09 \%$ \\
\hline
\end{tabular}

$C T_{w}$ representa o custo total obtido na execução $w$, em que $w=1, \ldots, 5$. $\mathrm{O}$ custo total mínimo equivale a $C T_{\min }=\min \left\{C T_{w}\right\}, \quad$ o custo total médio a $C T_{\text {med }}=\sum_{w=1}^{5} C T_{w} / 5$ e o custo total máximo a $C T_{\max }=\max \left\{C T_{w}\right\}$. Já a variação percentual é dada por $V a-$ riação $=100 \times \frac{C T_{\mathrm{med}}-C T_{\min }}{C T_{\min }}$.

As estratégias STJ-E1 e STJ-E3 apresentaram as menores variações percentuais (inferiores a 7,87\%). Já a estratégia STJ-E2 apresentou a pior variação percentual, englobando soluções com penalidades associadas a não cobertura de todos os voos.

As estratégias combinadas com o cruzamento aleatório 
em múltiplos pontos (CA-MP) apresentaram uma variação percentual inferior a $12,23 \%$. Desconsiderando-se a combinação com a estratégia STJ-E2, o operador CA-MP mostrou-se ainda mais robusto, com uma variação percentual inferior a $4,41 \%$.

\section{CONCLUSÕES}

Esta pesquisa abordou o Problema de Programação de Tripulante (PPT), de importância fundamental no planejamento operacional das empresas aéreas. Uma metodologia para solução integrada do PPT é proposta, em que se elimina a necessidade de resolver inicialmente o Problema de Determinação das Viagens (PDV). As escalas dos tripulantes são formadas a partir do agrupamento das jornadas (e não das viagens) com outras atividades (tais como: folgas, treinamento, exames periódicos, reuniões e férias), levando a uma solução final com melhor qualidade, além de atender à legislação trabalhista brasileira.

Para este propósito, um Algoritmo Genético Híbrido $(\mathrm{AGH})$ associado a um procedimento de busca em profundidade e a um modelo de programação linear inteira foi desenvolvido. A metodologia proposta mostrou-se capaz de levar a soluções factíveis e eficientes para as instâncias consideradas, com tempos de processamento reduzidos (da ordem de 1 a 8 minutos).

Os resultados dos testes e das aplicações práticas (Tabelas 3 e 4) indicam que as estratégias STJ-E2 e STJ-E3, propostas nesta pesquisa para aplicação da heurística construtiva (Seção 3.2.3), foram mais eficazes do que a estratégia STJ-E1, adotada por Souai e Teghem (2009). Além disso, a estratégia de cruzamento CA-MP, resultante de inovações aplicadas às estratégias (CS-MP e CP-MP, Seção 3.2.5) propostas por Souai e Teghem (2009), apresentou resultados mais eficazes do que as demais estratégias (CS-MP, CP-MP e CA-UP) e uma boa robustez (Tabela 5).

Embora os testes realizados tenham considerado a existência de apenas uma base domiciliar, a metodologia proposta pode ser utilizada para o caso de múltiplas bases domiciliares, tornando-se necessário especificar os tripulantes associados a cada base domiciliar.

É importante observar que a legislação brasileira considerada na definição das restrições do PPT (Seção 2) está de acordo com as regras de segurança, regulamentações trabalhistas e acordos sindicais adotados internacionalmente, o que permite a adaptação do modelo proposto para a solução do PPT de empresas aéreas de outros países.

\section{AGRADECIMENTOS}

Os autores agradecem à CAPES (Coordenação de Aperfeiçoamento de Pessoal de Nível Superior), ao CNPq (Conselho Nacional de Desenvolvimento Científico e Tecnológico) e ao LPT/EPUSP (Laboratório de Planejamento e Operação de Transportes da EPUSP).

\section{REFERÊNCIAS BIBLIOGRÁFICAS}

ANAC (2010) Lei do Aeronauta (7.183/84). Agência Nacional de Aviação Civil, Brasília, DF. Disponível em: < http://www.anac.gov.br/biblioteca/leis/lei7183\%20.pdf>. (Acesso em 4/1/2010).

Andersson, E.; E. Houses; N. Kohl e D. Wedelin (1998) Crew pairing optimization. Operations Research in Airline Industry. Boston: Kluwer Academic Publishers.
Barnhart, C.; A. Cohn; E. Johnson; D. Klabjan; G. Nemhauser e P. Vance (2003) Airline crew scheduling. Handbook of Transportation Science. Boston: Kluwer Scientific Publishers.

Cabral, L. A. F.; M. J. Freitas; N. Maculan e R. C. V. Pontes (2000) An heuristic approach for large scale crew scheduling problems at Rio-Sul airlines. Proceedings $40^{\text {th }}$ International Symposium of the AGIFORS, Istambul, Turquia. Disponível em: $<$ http://www.iceb.ufop.br/decom/prof/marcone/Publicacoes/RioSul_agifors.pdf $>$. (Acesso em 5/1/2010).

Chang, S. C. (2002) A new aircrew scheduling model for short-haul routes. Journal of Air Transport Management, v. 8, p. 249-260.

Cunha, C. B. (2006) Contribuição à modelagem de problemas de logística e transportes. Tese (Livre Docência), Departamento de Engenharia de Transportes, Escola Politécnica da USP, São Paulo, SP.

Feo, T. A. e M. G. C. Resende (1995) Greedy randomized adaptive search procedures. Journal of Global Optimization, v. 6, p. 109-133.

Gomes, W. P. (2009) Programação de tripulantes de aeronaves no contexto brasileiro. Dissertação (Mestrado), Departamento de Engenharia de Transportes, Escola Politécnica da USP, São Paulo, SP.

Gomes, W. P. e N. D. F. Gualda (2008) Otimização da formação de viagens no processo de alocação de tripulantes a aeronaves (crew pairing problem). Anais do XXII Congresso de Pesquisa e Ensino em Transportes, ANPET, Fortaleza, v. 1, p. 1010-1020.

Gopalakrishnan, B. e E. Johnson (2005) Airline crew scheduling: state-ofthe-art. Annals of Operations Research, v. 140, n. 2, p. 305-337.

Kohl, N. e S. E. Karisch (2004) Airline crew rostering: problem types, modeling and optimization. Annals of Operations Research, v. 127 , p. 223-257.

Lucic, P. e D. Teodorovic (2007) Metaheuristics approach to the aircrew rostering problem. Annals of Operations Research, v. 155, p. 311338 .

SNA (2010) Convenção coletiva de trabalho (aviação regular) 2010/2012. Sindicato Nacional dos Aeronautas, Rio de Janeiro, RJ. Disponível em: <http://www.aeronautas.org.br/images/stories/convcol/cc_2010_2012.pdf.> (Acesso em 4/1/2010).

Souai, N. e J. Teghem (2009) Genetic algorithm based approach for the integrated airline crew-pairing and rostering problem. European Journal of Operational Research, v. 199, p. 674-683.

Zeghal, F. M. e M. Minoux (2006) Modeling and solving a crew assignment problem in air transportation. European Journal of Operational Research, v. 175, p. 187-209. 